\title{
PARP inhibitor resistance and TP53 mutations in patients treated with olaparib for BRCA-mutated cancer: Four case reports
}

\author{
THOMAS COLLOT $^{1 *}$, JULIE NIOGRET $^{1 *}$, MARION CARNET $^{2}$, SANDY CHEVRIER $^{2}$, \\ ETIENNE HUMBLIN ${ }^{3}$, LAURE FAVIER ${ }^{1}$, LEILA BENGRINE-LEFEVRE ${ }^{1}$, \\ ISABELLE DESMOULINS $^{1}$, LAURENT ARNOULD ${ }^{4}$ and ROMAIN BOIDOT ${ }^{2,5}$ \\ ${ }^{1}$ Department of Oncology, ${ }^{2}$ Molecular Biology Unit, Department of Biology and Pathology of Tumors, \\ Georges-François Leclerc Cancer Center, UNICANCER, F-21079 Dijon; ${ }^{3}$ Centre de Recherche, \\ University Bourgogne Franche-Comté, F-21078 Dijon; ${ }^{4}$ Pathology Unit, Department of Biology and \\ Pathology of Tumors, Georges-François Leclerc Cancer Center, UNICANCER, F-21079 Dijon; \\ ${ }^{5}$ National Center of Scientific Research, Unit 6302, F-21000 Dijon, France
}

Received February 6, 2020; Accepted July 15, 2020

DOI: $10.3892 / \mathrm{mmr} .2020 .11713$

\begin{abstract}
Loss-of-function BRCA mutations are frequent in high-grade serous ovarian carcinoma. BRCA1 and -2 mutations lead to homologous recombination (HR) deficiency. Poly(ADP-ribose) polymerases (PARP) are enzymes involved in DNA repair. PARP inhibitors (PARPi) lead to DNA damage accumulation in cells deficient in HR. Olaparib (a PARPi) is currently used for the treatment of high-grade serous ovarian carcinoma with germline or somatic BRCA mutations; however, numerous patients do not respond or eventually develop resistance to these agents. The TP53 gene encodes the p53 protein, which is often referred to as the 'guardian of the genome'. TP53 mutations at diagnosis are known to promote resistance to chemotherapy. In the present study, four cases of patients with BRCA-mutated cancer treated with olaparib, who progressed following the PARPi treatment, are reported. Exome analyses were performed on a primary tumor biopsy at diagnosis, then on a progressing metastasis following olaparib treatment. Exome analyses following olaparib treatment identified de novo TP53 mutations, as well as increased frequencies of pre-existing TP53 mutations compared with the primary tumor. In HCT116 TP53 $3^{-1-}$ cells carrying BRCA2 pathogenic mutations, TP53 inactivating
\end{abstract}

Correspondence to: Dr Romain Boidot, Molecular Biology Unit, Department of Biology and Pathology of Tumors, Georges-François Leclerc Cancer Center, UNICANCER, 1 Rue Professeur Marion, F-21079 Dijon, France

E-mail: rboidot@cgfl.fr

*Contributed equally

Abbreviations: $\mathrm{HR}$, homologous recombination; $\mathrm{IC}_{50}$, half maximal inhibitory concentration; PARP, poly (ADP-ribose) polymerase; PARPi, PARP inhibitor

Key words: resistance, PARP inhibitors, TP53, BRCA-mutated cancer, olaparib mutations were associated with lower sensitivity to olaparib in vitro. Thus, inactivating TP53 mutations may be associated to olaparib resistance in the presence of BRCA mutations. In conclusion, the present findings demonstrated resistance to PARPi with de novo TP53 mutations that may be clinically relevant. As TP53 mutations are easily detectable with targeted next-generation sequencing panels, these may serve as surrogate markers for the onset of PARPi resistance in the context of routine patient management strategies.

\section{Introduction}

Germline mutations in the tumor-suppressive BRCA genes are associated with an increased familial risk of breast and ovarian cancer (1). Moreover, loss-of function BRCA mutations are found in $\sim 11 \%$ of tumors, most frequently (25\%) in high-grade serous ovarian adenocarcinoma (2). BRCA1 and -2 mutations have been discovered to lead to homologous recombination (HR) deficiency and to an accumulation of chromosomal aberrations that promote tumorigenesis $(3,4)$.

The treatment of high-grade serous ovarian cancer with germline or somatic BRCA1 or -2 mutations is predominantly based on poly(ADP-ribose) polymerase (PARP) inhibitors (PARPi), such as olaparib (5-7). The PARPi is used in the maintenance phase following responsiveness to platin-based chemotherapy and has been demonstrated to increase progression-free survival by $>11$ months compared with the placebo (5-7).

PARPs are enzymes involved in DNA repair, particularly in single-strand break repair. The use of PARPis leads to the accumulation of DNA damage in cells that are HR-deficient due to BRCA loss-of-function mutations, ultimately resulting in synthetic lethality $(8,9)$. Synthetic lethality refers to the effect that certain pharmacological inhibitors can have on a pair of genes, whereby the pharmacological inhibition of one gene causes cell death only if the other gene is mutated, as might be the case in a tumor cell, but not if the other gene is wild-type, as is the case in a healthy cell $(8,9)$. A number of mechanisms of PARPi resistance mechanisms have been identified, 
including the upregulation of PgP drug transporters (10), loss of p53-binding protein 1 (TP53BP1) function (11) or secondary mutations within BRCA1 or -2 genes (10).

The TP53 gene is a tumor-suppressive gene encoding the p53 protein (12). p53 functions as a transcription factor which is involved in the checkpoint transition between the $\mathrm{G}_{1}$ and $\mathrm{S}$ phases of the cell cycle (13). In the presence of DNA mutations that cannot be repaired, p53 promotes cell cycle arrest, induces proapoptotic signals and prevents tumor formation (11). Notably, the presence of TP53 mutations has been discovered to indicate resistance to chemotherapy (11).

In the present study, tumor samples from four patients with BRCA-mutated cancers treated with olaparib, who progressed following the PARPi treatment, including three individuals with ovarian cancers and one with breast cancer, were analyzed. The exome sequencing profiles of the progressing tumor were compared with the primary tumor tissue obtained at diagnosis.

\section{Materials and methods}

Exome sequencing. DNA extraction and exome sequencing from formalin-fixed paraffin-embedded (FFPE) samples were performed as described previously (14). DNA was extracted using the Maxwell-16 FFPE Plus LEV DNA purification kit (cat. no. AS1135; Promega Corporation) according to the manufacturer's protocol. DNA quality was assessed by spectrophotometry with absorbance measured at 230, 260 and $280 \mathrm{~nm}$. DNA was quantified by a Qubit fluorometric assay (cat. no. Q32850; Thermo Fisher Scientific, Inc.) according to the manufacturer's instructions.

Libraries were constructed from $200 \mathrm{ng}$ DNA and captured using the SureSelect Human All Exon v6 kit (Agilent) following the manufacturer's protocol. Paired-end (2x111 bases) sequencing was performed on a NextSeq500 device (Illumina, Inc.). Next, the sequences were aligned and annotated with the human $\mathrm{Hg} 19$ genome based on the SureSelect Human all Exon v6 manifest using the BWA and GATK algorithms. Only sequences with a read depth of $10 x$, a mutation allele frequency $>5 \%$, and a frequency in the general population inferior to $1 \%$ were retained for further analysis.

Cell culture. HCT116 TP53 ${ }^{--}$and BRCA2 mutated (c.8021dup, p.I2675fsTer6) (15) cells (kind gift from Professor Olivier Feron, UCLouvain, Brussels, Belgium) were cultured in high-glucose DMEM supplemented with $10 \%$ (vol/vol) fetal calf serum (Thermo Fisher Scientific, Inc.), 1\% penicillin, $1 \%$ streptomycin, $1 \%$ amphotericin B and 4 mM HEPES at $37^{\circ} \mathrm{C}$ with $5 \% \mathrm{CO}_{2}$. Transfection of pCMV-Neo-Bam plasmids containing wild-type p53 (negative control), p53 R175H or p53 R248W (12) obtained from Addgene, Inc. was performed as described previously (16). Briefly, cells were transfected with $0.5 \mu \mathrm{g}$ plasmid using Lipofectamine ${ }^{\circledR} 2000$ (Thermo Fisher Scientific, Inc.) according to the manufacturer's instructions. After $6 \mathrm{~h}$, culture medium was replaced by fresh medium. The next morning, cells were re-plated in new plates.

Western blotting. Transfection efficiency was verified by western blotting analysis as described previously (17). Protein concentration was assessed using the Bio-Rad DC Protein Assay kit (Bio-Rad Laboratories, Inc.). Then, $50 \mu \mathrm{g}$ protein/lane was denatured, loaded and separated via $12 \%$ SDS-PAGE and transferred onto nitrocellulose membranes (Schleicher \& Schuell Bioscience $\mathrm{GmbH}$ ). After blocking with 5\% non-fat milk in phosphate-buffered saline containing $0.1 \%$ Tween-20 (PBST) for $1 \mathrm{~h}$ at room temperature, membranes were incubated overnight at $4{ }^{\circ} \mathrm{C}$ with primary antibody $(1 \mu \mathrm{g} / \mathrm{ml})$ in PBST containing 5\% BSA. Afterwards, membranes were washed and incubated for $1 \mathrm{~h}$ at room temperature with secondary antibody diluted in PBST-5\% non-fat milk. After three additional washes with PBST, membranes were incubated with luminol reagent for $1 \mathrm{~min}$ at room temperature (cat. no. sc2048; Santa Cruz Biotechnology, Inc.). The following primary antibodies from Santa Cruz Biotechnology, Inc. were used: Mouse anti-p53 (1:1,000; cat. no. DO-1) and anti-HSC70 (1:1,000; cat. no. B-6). The following secondary antibodies were used: Peroxidase AffiniPure Goat polyclonal Peroxidase AffiniPure Goat polyclonal Anti-Mouse IgG (H+L) (1:10,000; cat. no. 115-035-003; Jackson ImmunoReseach Europe, Ltd.).

Half maximal inhibitory concentration $\left(I C_{50}\right)$ assessment. HCT116 $\mathrm{TP}^{2} 3^{-/}$cells were seeded at $20 \%$ confluence into 96-well plates $24 \mathrm{~h}$ after transfection. After $24 \mathrm{~h}$, cells were treated with $3 \mu \mathrm{g} / \mathrm{ml}$ oxaliplatin (Teva Pharmaceutical Industries Ltd.) for $72 \mathrm{~h}$ to induce DNA damage at $37^{\circ} \mathrm{C}$, then with titrating doses of olaparib (LC Laboratories) $(0-2,560 \mu \mathrm{M})$ for five days at $37^{\circ} \mathrm{C}$ in order to determine the $\mathrm{IC}_{50}$ of this drug. Cell viability was assessed using crystal violet staining (15). A total of $50 \mu \mathrm{l}$ $1 \%$ crystal violet solution (Sigma-Aldrich; Merck KGaA) was added directly to the cells. After $20 \mathrm{~min}$ at room temperature, the crystal violet was removed and cells were washed with tap water. Then, $100 \mu 1$ DMSO was added to dissolve the crystal violet. Absorbance was calculated at $590 \mathrm{~nm}$ with a DU370 UV-Vis spectrophotometer (Beckman Coulter, Inc.)

A two-way ANOVA followed by a Greisser-Greenhouse correction was performed to determine the statistical differences between the groups using Graph Pad Prism software (v8.3.0; GraphPad Software, Inc.). Data are presented as mean $\pm \mathrm{SD}$ of three independent repeats. $\mathrm{P}<0.05$ was considered to indicate a statistically significant difference.

\section{Results}

Presentation of cases. All patients were treated at the Georges-François Leclerc Cancer Center, Dijon, France. Patient 1 (Ovary \#1) was a 70-75-year-old woman diagnosed with ovarian cancer in February 2013. She had a past history of malaria and a family history of breast cancer on her maternal side. In February 2013, she underwent neoadjuvant chemotherapy (carboplatin-paclitaxel), interval surgery and adjuvant chemotherapy for an International Federation of Gynecology and Obstetrics stage-IIIc papillary serous ovarian bilateral cancer (diagnosed based on clinical pathological characteristics), and experienced complete remission. She presented with peritoneal relapse 11 months later diagnosed by CT-scan, which was treated with Platin-based chemotherapy (carboplatin-paclitaxel for six treatment cycles). Genomic DNA analysis identified a constitutional BRCA1 gene mutation (c.3839_3841delCTC; p.S1280_Q1281delinsTer). An anti-angiogenic (bevacizumab) was added to the treatment regimen in April 2015, with a partial tumor response after six courses. In November 2015, olaparib was introduced as maintenance chemotherapy until March 2016, when the patient presented with a fast peritoneal and pancreatic 

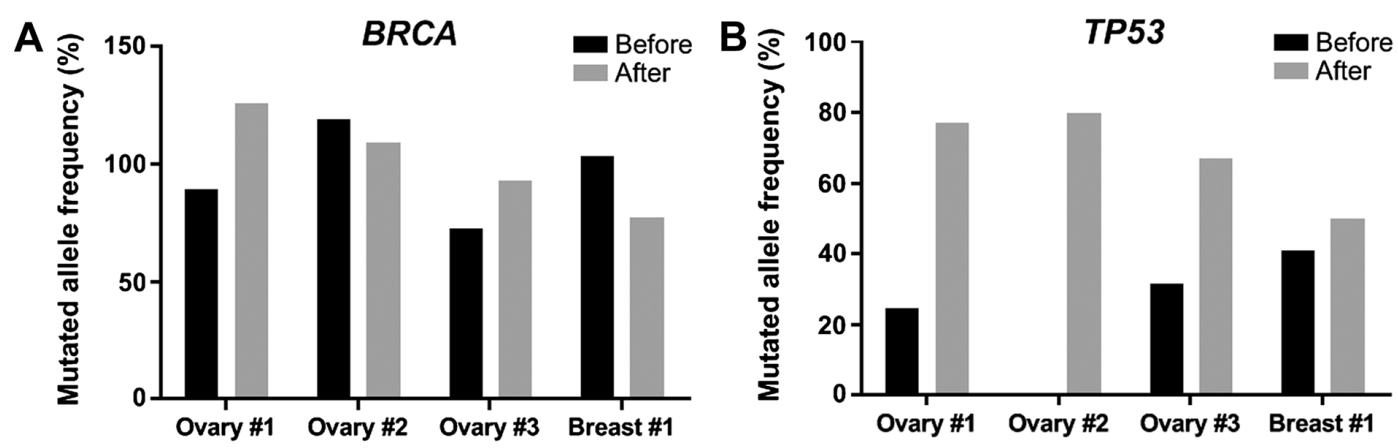

Figure 1. BRCA and TP53 mutant allele frequencies before and after treatment with olaparib. Mutated allele frequency divided by tumor cell content of (A) BRCA and (B) TP53 in tumors before and after treatment with olaparib in four patients. While changes in BRCA mutation frequencies were not consistent across all patients, TP53 mutations developed (ovary\#2) or increased in frequency (ovary \#1 and \#3 and breast \#1) following olaparib treatment.

relapse with ascites and biliary compression indicated by CT-scan. Chemotherapy was administered (weekly carboplatin) but had to be stopped after one course due to rapid deterioration of the patient, who died in May 2016. The first next-generation sequencing (NGS) analysis was performed in April 2015 on the primary tumor. The second analysis was performed using an ascites effusion in April 2016, after olaparib treatment ended.

Patient 2 (Ovary \#2) was a 50-55-year-old woman treated with six courses of platin-based neoadjuvant chemotherapy (carboplatin-paclitaxel) and complete resection surgery for a papillary serous ovary cancer (diagnosed via pathological examination) in October 2010. She had a family history of breast cancer and shared a known BRCA2 mutation (c.7845+1G>T) with her two sisters. She relapsed two years later, in 2012, and was treated with the same platin-based chemotherapy and complete surgery. In May 2013, she received a third-line treatment with carboplatin-gemcitabine-bevacizumab; carboplatin allergy arose at the third course and treatment was stopped. A new relapse in May 2014 detected by CT-scan was treated by oxaliplatin-gemcitabine for six courses with a complete tumor response. Finally, in February 2015, she presented with carcinomatous meningitis detected by CT-scan that was treated by intrathecal methotrexate, brain radiotherapy and weekly cisplatin. Based on the clinical and imaging partial response, olaparib maintenance treatment was started in July 2015 and terminated in August 2016, when the patient relapsed. She died in September 2016. NGS analyses were performed in 2015 on the tumor collected on the first surgery and in August 2016 on cerebrospinal liquid.

Patient 3 (Ovary \#3) was a 70-75-year-old female. She had a family history of ovarian cancer and her mother had ovarian cancer at 40 years old. She underwent three neoadjuvant platin-based chemotherapy (carboplatin-paclitaxel) courses in July 2013, interval complete surgery and adjuvant chemotherapy (carboplatin-paclitaxel), for a papillary serous stage IIIc ovarian cancer. She first relapsed in November 2014 and was treated with carboplatin-liposomal doxorubicin for five courses. She presented with an in situ breast cancer detected by mammography, which was treated with surgery and radiotherapy in March 2015. Germline analysis identified a germinal BRCA2 mutation (c.2066_2069delGTAA, p.S689KfsX11). Chemotherapy resumed with carboplatin-gemcitabine-bevacizumab in May 2016 due to a new pelvic progression detected by CT-scan. The tumor responded to the treatment and olaparib maintenance started in September 2016. In May 2018, she was still undergoing olaparib, with dose reduction due to hematologic toxicity. In the interval, she underwent a mesenteric node resection for a single and localized progression in March 2018. NGS analyses were performed in May 2016 on the primary tumor tissue, then on the mesenteric node in March 2018. This patient died in December 2018.

Patient 4 (Breast \#1) was a 50-55-year-old female. She auto-palpated a left breast lesion in March 2015, which was later diagnosed via biopsy as a triple-negative infiltrative breast carcinoma with axillary node infiltration. She underwent neoadjuvant chemotherapy with three courses of 5-fluorouracil-epirubicin-cyclophosphamide and three courses of docetaxel, and breast surgery (mastectomy and axillary lymph node dissection), which demonstrated clear signs of tumor regression. Treatment was completed in October 2015 with radiotherapy of the chest wall and lymphatic areas. During radiotherapy, she presented with a cervical node which identified as triple-negative breast cancer metastasis. Treatment with capecitabine was introduced in November 2015 until May 2016, when the cervical node clinically progressed. NGS analysis identified a BRCA1 somatic mutation (c.2783G >T, p.G928V), and treatment with cisplatin-gemcitabine-bevacizumab was initiated in May 2016. In November 2016, considering the observed complete remission, maintenance by off-label (olaparib was only indicated for ovarian cancer at this date) olaparib was introduced. She relapsed in April 2017 with pleural effusion and hepatic metastasis detected by CT-scan. Olaparib treatment was stopped and chemotherapy with Halaven ${ }^{\circledR}$ was initiated in April 2017. A total of five courses were administered, but the patient died in September 2017. NGS analyses were performed on the primary tumor in September 2015 and on the cervical metastasis node biopsy in May 2017.

$N G S$ analysis. Exome analyses were performed on the primary tumor sample at diagnosis, then on a progressing lesion following olaparib treatment. Allelic frequencies of all mutations observed in both lesions of each patient are reported in Tables I-IV. Previously described resistance mechanisms such as a new BRCA1 or BRCA2 mutation, or TP53BP1 loss-of-function mutations were not observed following olaparib treatment. The only feature shared by all four patients was an enrichment in TP53 mutations following treatment. Indeed, all tumors had a BRCA mutation, whereas 3 out of 4 had low-frequency TP53 mutations ( $<50 \%$ of tumor cells harboring a TP53 mutation). In the Ovary \#2 patient, the tumor only had a BRCA 2 mutation without any TP53 mutations prior to olaparib treatment (Fig. 1; Table II). 
Table I. Allelic frequency of mutations observed before and after olaparib treatment in Ovary \#1.

\begin{tabular}{|c|c|c|c|c|}
\hline Gene & $\begin{array}{l}\text { Nucleotide } \\
\text { mutation }\end{array}$ & $\begin{array}{l}\text { Protein } \\
\text { mutation }\end{array}$ & $\begin{array}{l}\text { Relative }^{\mathrm{a}} \text { allelic } \\
\text { frequency before } \\
\text { olaparib, \% }\end{array}$ & $\begin{array}{l}\text { Relative }^{\mathrm{b}} \text { allelic } \\
\text { frequency after } \\
\text { olaparib, \% }\end{array}$ \\
\hline ABL1 & c. $2486 \mathrm{C}>\mathrm{T}$ & p.P829L & 69 & 0 \\
\hline ABL2 & c. $47 \mathrm{~A}>\mathrm{C}$ & p.N1860S & 0 & 57 \\
\hline $\begin{array}{l}\alpha \text { thalassemia/mental retardation } \\
\text { syndrome } \mathrm{X} \text {-linked }\end{array}$ & c. $5579 \mathrm{~A}>\mathrm{G}$ & p.N1860S & 77 & 81 \\
\hline BRCA1 & c.3839_3841delCTC & p.S1280_Q1281delinsTer & 88 & $126^{\mathrm{c}}$ \\
\hline BRCA1 & c.3844_3845insCG & p.E1282AfsTer26 & 82 & 100 \\
\hline $\begin{array}{l}\text { BRCA1 interacting protein C-terminal } \\
\text { helicase } 1\end{array}$ & c. $2876 \mathrm{C}>\mathrm{A}$ & p.P959Q & 0 & 27 \\
\hline Lysine-specific demethylase 6A & c. $2158 \mathrm{C}>\mathrm{A}$ & p.P720T & 0 & 18 \\
\hline $\begin{array}{l}\text { Low-density lipoprotein } \\
\text { receptor-related 1B }\end{array}$ & c. $9532 \mathrm{G}>\mathrm{A}$ & p.A3178T & 67 & 60 \\
\hline PI3K catalytic subunit $\gamma$ isoform & c. $9532 \mathrm{G}>\mathrm{A}$ & p.N522S & 8 & 76 \\
\hline Equilibrative nucleoside transporter 1 & c. $647 \mathrm{~T}>\mathrm{C}$ & p.I216T & 100 & 79 \\
\hline Tumor p53 & c. $916 \mathrm{C}>\mathrm{T}$ & p.R306T & 24 & 77 \\
\hline
\end{tabular}

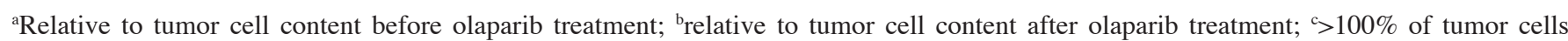
contained the mutated allele, suggesting amplification of the mutated allele. Tumor cell content before olaparib, 35\%; after olaparib, $90 \%$.

Table II. Allelic frequency of mutations observed before and after olaparib treatment in Ovary \#2.

\begin{tabular}{|c|c|c|c|c|}
\hline Gene & $\begin{array}{l}\text { Nucleotide } \\
\text { mutation }\end{array}$ & $\begin{array}{l}\text { Protein } \\
\text { mutation }\end{array}$ & $\begin{array}{l}\text { Relative }^{\mathrm{a}} \text { allelic } \\
\text { frequency before } \\
\text { olaparib, } \%\end{array}$ & $\begin{array}{c}\text { Relative }^{\mathrm{b}} \text { allelic } \\
\text { frequency after } \\
\text { olaparib, \% }\end{array}$ \\
\hline ABL2 & c. $2789 A>G$ & p.K930R & $143^{\mathrm{c}}$ & 46 \\
\hline Adenomatous polyposis coli protein & c. $7504 \mathrm{G}>\mathrm{A}$ & p.G2502S & $110^{c}$ & 11 \\
\hline Tyrosine-protein kinase receptor UFO & c. $1777 \mathrm{G}>\mathrm{C}$ & p.D593H & 0 & 44 \\
\hline BRCA2 & c. $7617+1 \mathrm{G}>\mathrm{T}$ & Splicing & $119^{c}$ & $109^{c}$ \\
\hline $\mathrm{G}_{1} / \mathrm{S}$-specific cyclin-D3 & c. $759 \mathrm{G}>\mathrm{T}$ & p.E253D & $130^{\mathrm{c}}$ & 56 \\
\hline $\begin{array}{l}\text { Histone-lysine N-methyltransferase, } \\
\text { H3 lysine-79 specific }\end{array}$ & c. $4415 \mathrm{C}>\mathrm{T}$ & p.P1472L & 57 & 0 \\
\hline Terminal nucleotidyltransferase $5 \mathrm{C}$ & c. $201 \mathrm{C}>\mathrm{G}$ & p.H67Q & $283^{c}$ & $111^{\mathrm{c}}$ \\
\hline FLT3 & c. $970 \mathrm{G}>\mathrm{A}$ & p.D324N & $161^{\mathrm{c}}$ & 103 \\
\hline FLT4 & c. $3962 \mathrm{G}>\mathrm{A}$ & p.R1321Q & $133^{\mathrm{c}}$ & 98 \\
\hline Transcriptional activator GLI3 & c. $3083 \mathrm{G}>\mathrm{T}$ & p.S1028I & $127^{\mathrm{c}}$ & 49 \\
\hline MAP2K3 & c.927delC & p.A311QfsTer4 & 0 & 16 \\
\hline PMS1 homolog 2 & c. $1531 \mathrm{~A}>\mathrm{G}$ & p.T511A & $109^{c}$ & 89 \\
\hline Tumor p53 & c. $672+1 \mathrm{G}>\mathrm{T}$ & Splicing & 0 & 44 \\
\hline
\end{tabular}

${ }^{a}$ Relative to tumor cell content before olaparib treatment; ${ }^{b}$ relative to tumor cell content after olaparib treatment; ${ }^{c}>100 \%$ of tumor cells contained the mutated allele, suggesting amplification of the mutated allele. Tumor cell content before olaparib, 35\%; after olaparib, 90\%. FLT, Fms-related receptor tyrosine kinase.

After progression under olaparib, the allele frequencies of BRCA1 and BRCA2 mutations varied between patients. Indeed, some patients (Ovary \#1 and 3) had an increase in the allelic frequency of BRCA mutations, whereas others (Ovary \#2, Breast \#1) experienced a decrease. However, in the case of TP53, de novo mutations were observed (Ovary \#2), as well as increased frequencies of mutations already present in the primary tumor (Ovary \#1 and 3, Breast \#1) (Fig. 1; Tables I-IV). The allelic frequency of each mutation relative to tumor cell content (assessed by a pathologist) before and after olaparib treatment for BRCA genes (Fig. 1A) and for the TP53 gene (Fig. 1B) was also evaluated. Thus, the findings suggested that the enrichment in TP53 mutations may be a marker of resistance to olaparib in these patients. 
Table III. Allelic frequency of mutations observed before and after olaparib treatment in Ovary \#3.

\begin{tabular}{|c|c|c|c|c|}
\hline Gene & $\begin{array}{l}\text { Nucleotide } \\
\text { mutation }\end{array}$ & $\begin{array}{l}\text { Protein } \\
\text { mutation }\end{array}$ & $\begin{array}{l}\text { Relative }^{\mathrm{a}} \text { allelic } \\
\text { frequency before } \\
\text { olaparib, } \%\end{array}$ & $\begin{array}{c}\text { Relative }^{\mathrm{b}} \text { allelic } \\
\text { frequency after } \\
\text { olaparib, \% }\end{array}$ \\
\hline $\begin{array}{l}\text { AT-rich interactive } \\
\text { domain-containing protein } 2\end{array}$ & c. $3499 \mathrm{~A}>\mathrm{T}$ & p.T1167S & 0 & 18 \\
\hline Telangiectasia and & c.5739_5744delACCAGA & p.R1913_D1915delinsS & 63 & 51 \\
\hline Rad3-related protein & c. $5746 \mathrm{~T}>\mathrm{A}$ & p.T1916N & 63 & 51 \\
\hline Axin 2 & c. $2120 \mathrm{~T}>\mathrm{G}$ & p.1707G & 0 & 18 \\
\hline $\begin{array}{l}\text { Tyrosine-protein kinase } \\
\text { UFO precursor }\end{array}$ & c. $2334-1 \mathrm{G}>\mathrm{A}$ & Splicing & 0 & 34 \\
\hline BRCA1 & c.2066_2069delGTAA & p.S689KfsTer11 & 73 & 93 \\
\hline $\mathrm{G}_{1} / \mathrm{S}$-specific cyclin-D1 & c. $806 \mathrm{~A}>\mathrm{C}$ & p.K269T & 0 & 10 \\
\hline Death domain-associated protein & c. $113 \mathrm{~A}>\mathrm{C}$ & p.H38P & 74 & 0 \\
\hline $\begin{array}{l}\text { Excision repair cross- } \\
\text { complementing excision repair } 2\end{array}$ & c. $1444 \mathrm{~A}>\mathrm{C}$ & p.T482P & 0 & 21 \\
\hline FGFR2 & c. $1777 \mathrm{C}>\mathrm{T}$ & p.R593C & 99 & 35 \\
\hline FGFR3 & c. $1351 \mathrm{C}>\mathrm{T}$ & p.P451S & 43 & 76 \\
\hline GATA1 & c. $685 \mathrm{G}>\mathrm{T}$ & p.G229C & 0 & 18 \\
\hline Janus kinase 2 & c. $2538 \mathrm{G}>\mathrm{C}$ & p.E846D & 81 & 100 \\
\hline $\begin{array}{l}\text { Low-density lipoprotein } \\
\text { receptor-related } 1 \mathrm{~B}\end{array}$ & c. $12047 \mathrm{C}>\mathrm{T}$ & p.P4016L & 70 & 45 \\
\hline MSH2 & c. $815 \mathrm{C}>\mathrm{T}$ & p.A272V & 73 & 46 \\
\hline MSH6 & c. $998 \mathrm{C}>\mathrm{T}$ & p.T333Ile & 64 & 48 \\
\hline Protein polybromo-1 & c. $437 \mathrm{G}>\mathrm{A}$ & p.R146Q & 80 & $113^{\mathrm{c}}$ \\
\hline PI3K catalytic subunit $\alpha$ & c. $335 \mathrm{~T}>\mathrm{C}$ & p.I112T & 23 & 0 \\
\hline Runt-related transcription factor 1 & c. $1270 \mathrm{~T}>\mathrm{G}$ & p.S424A & 0 & 59 \\
\hline Stromal antigen 2 & c. $838 \mathrm{G}>\mathrm{T}$ & p.E280Ter & 0 & 18 \\
\hline TP53 & c. $105 \mathrm{G}>\mathrm{C}$ & p.L35F & 26 & 91 \\
\hline TP53 & c.108_112dupGTCCC & p.Q38ArgfsTer8 & 31 & 67 \\
\hline
\end{tabular}

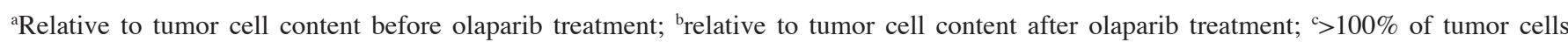
contained the mutated allele, suggesting amplification of the mutated allele. Tumor cell content before olaparib, 70\%; after olaparib, $85 \%$. FGFR, fibroblast growth factor receptor; MSH, human mutS homolog; TP53, tumor p53.
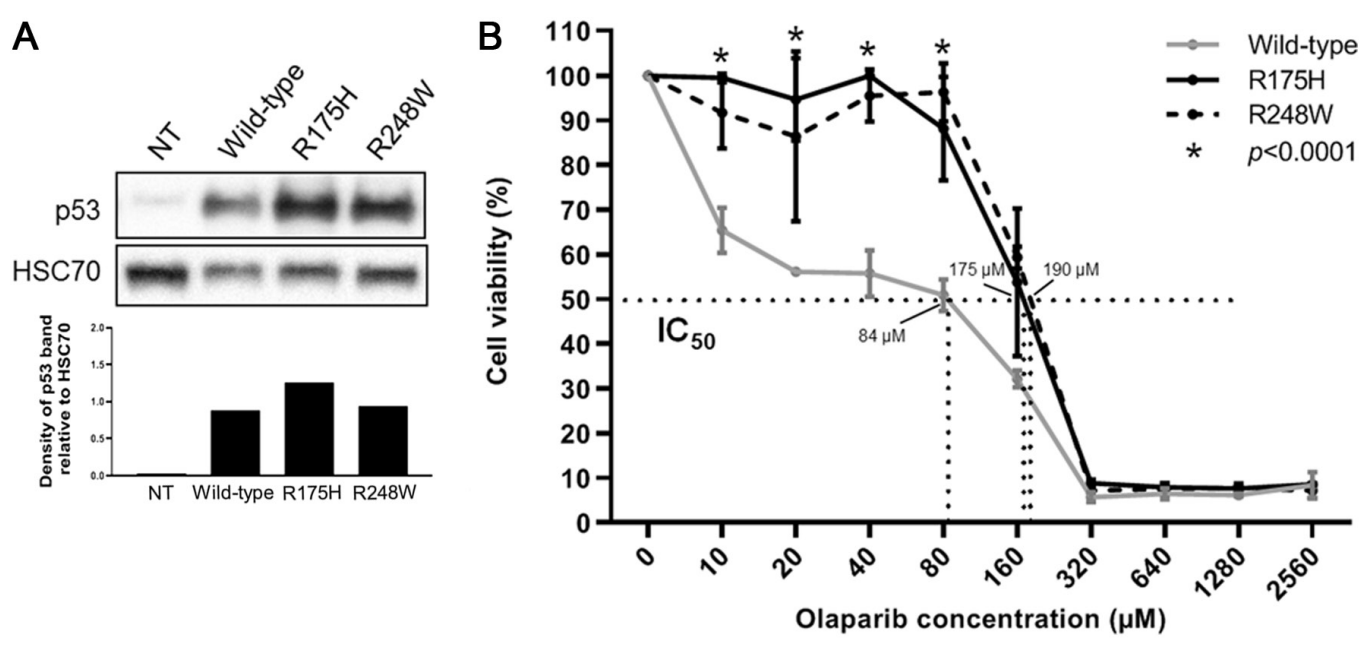

Figure 2. Sensitivity to olaparib according to TP53 status in a cell line with a BRCA2 pathogenic mutation. (A) Western blotting analysis demonstrating the expression levels of p53 following the transfection with plasmids containing wild-type TP53 or TP53 carrying inactivating mutations R175H and R248W in HCT116 TP5 $3^{-/}$cells. The expression levels of each protein were similar to each other. (B) Viability of HCT116 cells following the transfection with wild-type TP53, or TP53 carrying inactivating mutations $\mathrm{R} 175 \mathrm{H}$ and $\mathrm{R} 248 \mathrm{~W}$ and olaparib titration. The $\mathrm{IC}_{50}$ of olaparib was higher in the $\mathrm{R} 175 \mathrm{H}$ and $\mathrm{R} 248 \mathrm{~W}$ groups compared with the wild-type group $\left(175,190\right.$ and $84 \mu \mathrm{M}$, respectively). ${ }^{*} \mathrm{P}<0.0001$. IC $\mathrm{C}_{50}$, half maximal inhibitory concentration; NT, not transfected 
Table IV. Allelic frequency of mutations observed before and after olaparib treatment in Breast \#1.

\begin{tabular}{|c|c|c|c|c|}
\hline Gene & $\begin{array}{l}\text { Nucleotide } \\
\text { mutation }\end{array}$ & $\begin{array}{l}\text { Protein } \\
\text { mutation }\end{array}$ & $\begin{array}{l}\text { Relative }^{\mathrm{a}} \text { allelic } \\
\text { frequency before } \\
\text { olaparib, } \%\end{array}$ & $\begin{array}{c}\text { Relative }^{\mathrm{b}} \text { allelic } \\
\text { frequency after } \\
\text { olaparib, \% }\end{array}$ \\
\hline ABL1 & c. $3296 \mathrm{~A}>\mathrm{C}$ & p.K1099T & 0 & 56 \\
\hline AT-rich interaction domain $1 \mathrm{~A}$ & c. $4031 \mathrm{C}>\mathrm{G}$ & p.S1344C & 0 & 19 \\
\hline BRCA1-associated RING domain 1 & c. $1972 \mathrm{C}>\mathrm{T}$ & p.R658C & 36 & 81 \\
\hline BRCA1 & c. $2783 \mathrm{G}>\mathrm{T}$ & p.G928V & $104^{c}$ & 77 \\
\hline CREB-binding protein & c. $2111 \mathrm{C}>\mathrm{A}$ & p.P704Q & 22 & 0 \\
\hline Catenin $\alpha 1$ & c. $1283 \mathrm{~A}>\mathrm{G}$ & p.N428S & 99 & 69 \\
\hline DNA methyltransferase $3 \alpha$ & c. $89 \mathrm{~A}>\mathrm{C}$ & p.E30A & $107^{\mathrm{c}}$ & $116^{\mathrm{c}}$ \\
\hline E1A binding protein p300 & c. $631 \mathrm{G}>\mathrm{A}$ & p.G211S & $108^{c}$ & $113^{\mathrm{c}}$ \\
\hline EPH receptor A2 & c. $2627 \mathrm{G}>\mathrm{A}$ & p.R876H & $101^{\mathrm{c}}$ & $101^{\mathrm{c}}$ \\
\hline Erb-b2 receptor tyrosine kinase 3 & c. $1981 G>A$ & p.G661S & $106^{\mathrm{c}}$ & $114^{\mathrm{c}}$ \\
\hline Fanconi anemia group A & c. $3427 \mathrm{C}>\mathrm{G}$ & p.L1143V & $111^{\mathrm{c}}$ & $107^{\mathrm{c}}$ \\
\hline Fms-related receptor tyrosine kinase 4 & c. $1921 \mathrm{C}>\mathrm{T}$ & p.P641S & 12 & 41 \\
\hline Insulin receptor substrate 2 & c. $2153 \mathrm{G}>\mathrm{C}$ & p.R718T & 47 & 0 \\
\hline Kinase insert domain receptor & c. $2961 \mathrm{~A}>\mathrm{C}$ & p.E987D & 0 & 23 \\
\hline Myeloid cell leukemia sequence 1 & c. $680 \mathrm{C}>\mathrm{T}$ & p.A227V & 100 & 0 \\
\hline Multiple endocrine neoplasia I & c. $527 \mathrm{G}>\mathrm{A}$ & p.R176Q & 63 & 71 \\
\hline Human mutS homolog 6 & c. $2633 \mathrm{~T}>\mathrm{C}$ & p.V878A & 0 & 29 \\
\hline mTOR & c. $277 \mathrm{C}>\mathrm{A}$ & p.L93I & 0 & 67 \\
\hline Nibrin & c. $628 \mathrm{G}>\mathrm{T}$ & p.V210F & 0 & 46 \\
\hline NOTCH2 & c.17_18delCC & p.P6RfsTer27 & 63 & 0 \\
\hline PI3K catalytic subunit $\gamma$ isoform & c. $1025 \mathrm{~A}>\mathrm{G}$ & p.H342R & 0 & 41 \\
\hline ROS proto-oncogene 1 & c.5483_5486delTCAG & p.F1828Ter & 47 & 0 \\
\hline Equilibrative nucleoside transporter 1 & c. $911 \mathrm{~T}>\mathrm{C}$ & p.I304T & $108^{c}$ & $107^{\mathrm{c}}$ \\
\hline Tumor p53 & $\begin{array}{l}\text { c.403_421dupTGCCAA } \\
\text { CTGGCCAAGACCT }\end{array}$ & p.C141LfsTer14 & 41 & 50 \\
\hline $\mathrm{X}$-ray repair cross complementing 2 & c. $283 \mathrm{~A}>\mathrm{G}$ & p.I95V & 13 & 21 \\
\hline
\end{tabular}

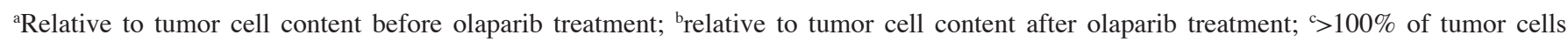
contained the mutated allele, suggesting amplification of the mutated allele. Tumor cell content before olaparib, 90\%; after olaparib, $70 \%$.

In vitro analysis. The human HCT116 colorectal carcinoma cell line with a BRCA2 pathogenic mutation (c.8021dup, p.I2675fsTer6) and TP53 deficiency was used to determine whether mutations in TP53 could be a marker of progression following olaparib treatment in the presence of BRCA mutations. HCT116 is a cell line with a TP53-deficient variant and a pathogenic BRCA mutation (15). HCT116 cells transfected with the mutant R175H and R248W TP53 (Fig. 2A) were significantly more resistant to olaparib compared with wild-type TP53-transfected cells $(\mathrm{P}<0.0001$; Fig. 2B); the calculated $\mathrm{IC}_{50}$ values were 175,190 and $84 \mu \mathrm{M}$ for R175H, R248W and WT, respectively (Fig. 2B). Thus, these results indicated that inactivating TP53 mutations may be associated with olaparib resistance in the presence of BRCA mutations, supporting the aforementioned clinical observations (TP53 mutation appearance or enrichment in progressing disease under olaparib treatment).

\section{Discussion}

Patients carrying mutations in BRCA genes are predisposed to high incidence rates of breast and ovarian cancer (1). BRCA genes are involved in the HR pathway, which is required for the repair of spontaneous double-stranded breaks that arise during DNA replication (18). Defects in HR result in an accumulation of chromatid breaks and cells that cannot repair chromatid breaks by HR become dependent on other alternative repair pathways (e.g. non-homologous end joining) (19). HR-deficient cells have exhibited acute sensitivity to PARPi-induced cell death (19), and the loss of PARP activity prevented the repair of single-stranded breaks, which were then converted into double-stranded breaks during DNA replication. The ability of PARPi to selectively kill HR-deficient cells is currently used for the treatment of breast and ovarian cancers with BRCA1 or -2 mutations (20). Overall, $\sim 15-20 \%$ of patients with epithelial ovarian cancer harbor germline or somatic BRCA mutations (21). However, some of these patients do not respond or eventually develop resistance to PARPis (5-7). The most common mechanism of resistance to these agents in BRCA-mutated cancer is secondary intragenic mutation restoring BRCA protein functionality (22). Additional mechanisms of resistance have been described, such as loss of TP53BP1 (11). Nevertheless, the clinical relevance of these 
mechanisms has not been demonstrated in patients with BRCA-mutated cancer.

The p53 protein is an important tumor suppressor encoded by the TP53 gene (12). p53 is a crucial factor in the cellular response to DNA damage (12). When an external event (e.g. mutagenic agent exposure, mutations induced by polymerase errors) induces genome alterations towards tumorigenesis, the expression of functional p53 is essential (21). When DNA damage cannot be repaired, p53 signaling induces apoptosis. Mutations in the TP53 gene result in failure of the p53 signaling (23). There is evidence to suggest that homozygous BRCA deficiency induced cell death by activating a p53-dependent checkpoint. However, the impairment of this checkpoint resulting from p53 loss removes the cell-lethal effects of BRCA deficiency $(24,25)$. Breast cancers from human mutated BRCA carriers have an increased frequency of TP53 mutations (26) and high-grade ovarian cancers often harbor TP53 mutations (27).

The present study documented the case of four patients for whom progression under PARPi treatment was suggested to be associated with the enrichment or emergence of TP53 mutations. Moreover, these observations were supported by in vitro experiments in which deleterious TP53 mutations were associated with reduced sensitivity to PARPi. In addition, the frequencies of pathogenic BRCA mutations varied across these patients after treatment. This phenomenon may be explained by clonal selection of PARPi-resistant clones. Indeed, the resistance mutation could be in the same cancer cell as the BRCA mutation, or in another cancer cell clone containing fewer BRCA mutations.

As the present study was based on clinical observations with a limited number of cases, it cannot be claimed that TP53 mutations are a mechanism of resistance or a clinical marker of progression. In the clinical setting, routine detection of plasma TP53 mutations could easily be achieved with NGS analysis. Thus, the emergence of de novo TP53 mutations or enrichment in pre-existing mutations may represent a marker of progression in patients under olaparib treatment.

\section{Acknowledgements}

The authors thank Dr Isabel Gregoire, Georges-François Leclerc Cancer Center (Dijon, France), for editing the manuscript.

\section{Funding}

No funding was received.

\section{Availability of data and materials}

The datasets used and/or analyzed during the current study are available from the corresponding author on reasonable request.

\section{Authors' contributions}

TC and JN made substantial contributions to conception and design of the study and acquisition, analysis and interpretation of data. SC performed the exome analysis. MC and $\mathrm{EH}$ performed the in vitro analysis. LF, LBL and ID treated the patients. LA performed the histological analysis and tumor cell assessment. RB designed the study, supervised the study and wrote the manuscript. All authors read and approved the final manuscript.

\section{Ethics approval and consent to participate}

All patients provided written informed consent for the use of genomic analysis results in research. Patient confidentiality was maintained and analysis was performed in compliance with the Declaration of Helsinki. The present study was approved by the Institutional Ethics Review Board of The Georges-François Leclerc Cancer Center (Dijon, France).

\section{Patient consent for publication}

The local ethics committee of The Georges-François Leclerc Center waives the necessity of patient consent for publication because the patients have died and as the content of the publication does not provide any identifying data on the patients, the establishment does not wish to disturb the patient's family in these unfortunate circumstances.

\section{Competing interests}

The authors declare that they have no competing interests.

\section{References}

1. Paul A and Paul S: The breast cancer susceptibility genes (BRCA) in breast and ovarian cancers. Front Biosci 19: 605-618, 2014.

2. Manchana T, Phoolcharoen N and Tantbirojn P: BRCA mutation in high grade epithelial ovarian cancers. Gynecol Oncol Rep 29: 102-105, 2019.

3. Bishop AJ and Schiestl RH: Role of homologous recombination in carcinogenesis. Exp Mol Pathol 74: 94-105, 2003.

4. Helleday T: Homologous recombination in cancer development, treatment and development of drug resistance. Carcinogenesis 31: 955-960, 2010

5. GelmonKA, TischkowitzM,Mackay H,SwenertonK, Robidoux A, Tonkin K, Hirte H, Huntsman D, Clemons M, Gilks B, et al: Olaparib in patients with recurrent high-grade serous or poorly differentiated ovarian carcinoma or triple-negative breast cancer: A phase 2, multicentre, open-label, non-randomised study. Lancet Oncol 12: 852-861, 2011.

6. Ledermann J, Harter P, Gourley C, Friedlander M, Vergote I, Rustin G, Scott C, Meier W, Shapira-Frommer R, Safra T, et al: Olaparib maintenance therapy in platinum-sensitive relapsed ovarian cancer. N Engl J Med 366: 1382-1392, 2012.

7. Kaufman B, Shapira-Frommer R, Schmutzler RK, Audeh MW, Friedlander M, Balmaña J, Mitchell G, Fried G, Stemmer SM, Hubert A, et al: Olaparib monotherapy in patients with advanced cancer and a germline BRCA1/2 mutation. J Clin Oncol 33: 244-250, 2015.

8. Farmer H, McCabe N, Lord CJ, Tutt AN, Johnson DA, Richardson TB, Santarosa M, Dillon KJ, Hickson I, Knights C, et al: Targeting the DNA repair defect in BRCA mutant cells as a therapeutic strategy. Nature 434: 917-921, 2005.

9. Ashworth A: A synthetic lethal therapeutic approach: Poly(ADP) ribose polymerase inhibitors for the treatment of cancers deficient in DNA double-strand break repair. J Clin Oncol 26: 3785-3790, 2008.

10. Choi YE, Meghani K, Brault ME, Leclerc L, He YJ, Day TA, Elias KM, Drapkin R, Weinstock DM, Dao F, et al: Platinum and PARP inhibitor resistance due to overexpression of microRNA-622 in BRCA1-mutant ovarian cancer. Cell Rep 14: 429-439, 2016.

11. Bunting SF, Callén E, Wong N, Chen HT, Polato F, Gunn A, Bothmer A, Feldhahn N, Fernandez-Capetillo O, Cao L, et al: 53BP1 inhibits homologous recombination in Brcal-deficient cells by blocking resection of DNA breaks. Cell 141: 243-254, 2010. 
12. Baker SJ, Markowitz S, Fearon ER, Willson JK and Vogelstein B Suppression of human colorectal carcinoma cell growth by wild-type p53. Science 249: 912-915, 1990.

13. Zhang M, Zhuang G, Sun X, Shen Y, Wang W, Li Q and Di W: TP53 mutation-mediated genomic instability induces the evolution of chemoresistance and recurrence in epithelial ovarian cancer. Diagn Pathol 12: 16, 2017.

14. Alsadoun N, MacGrogan G, Truntzer C, Lacroix-Triki M, Bedgedjian I, Koeb MH, El Alam E, Medioni D, Parent M, Wuithier P, et al: Solid papillary carcinoma with reverse polarity of the breast harbors specific morphologic, immunohistochemical and molecular profile in comparison with other benign or malignant papillary lesions of the breast: A comparative study of 9 additional cases. Mod Pathol 31: 1367-1380, 2018.

15. Dong Z, Dong H, Zhong X, Peng Z, Zhu X, Sun Y, Chen Y, Liu C, Yin X, Zhu G, et al: Development of a compehensive NGS workflow for the analysis of tumor BRCA1 and BRCA2 mutations and large rearrangements. J Genet Genome Res: Sept 28, 2015 (Epub ahead of print). doi: 10.23937/2378-3648/1410019.

16. Végran F, Boidot R, Solary E and Lizard-Nacol S: A short caspase-3 isoform inhibits chemotherapy-induced apoptosis by blocking apoptosome assembly. PLoS One 6: e29058, 2011.

17. Végran F, Mary R, Gibeaud A, Mirjolet C, Collin B, Oudot A, Charon-Barra C, Arnould L, Lizard-Nacol S and Boidot R: Survivin-3B potentiates immune escape in cancer but also inhibits the toxicity of cancer chemotherapy. Cancer Res 73: 5391-5401, 2013.

18. Andreassen PR, Ho GP and D'Andrea AD: DNA damage responses and their many interactions with the replication fork Carcinogenesis 27: 883-892, 2006.

19. Bryant HE, Schultz N, Thomas HD, Parker KM, Flower D, Lopez E, Kyle S, Meuth M, Curtin NJ and Helleday T: Specific killing of BRCA2-deficient tumours with inhibitors of poly(ADP-ribose) polymerase. Nature 434: 913-917, 2005.
20. Fong PC, Boss DS, Yap TA, Tutt A, Wu P, Mergui-Roelvink M, Mortimer P, Swaisland H, Lau A, O'Connor MJ, et al: Inhibition of poly(ADP-ribose) polymerase in tumors from BRCA mutation carriers. N Engl J Med 361: 123-134, 2009.

21. Cancer Genome Atlas Research Network: Integrated genomic analyses of ovarian carcinoma. Nature 474: 609-615, 2011.

22. Norquist B, Wurz KA, Pennil CC, Garcia R, Gross J, Sakai W, Karlan BY, Taniguchi T and Swisher EM: Secondary somatic mutations restoring BRCA1/2 predict chemotherapy resistance in hereditary ovarian carcinomas. J Clin Oncol 29: 3008-3015, 2011.

23. Levine AJ: Reviewing the future of the P53 field. Cell Death Differ 25: 1-2, 2018.

24. Hakem R, de la Pompa JL, Elia A, Potter J and Mak TW: Partial rescue of Brca1 (5-6) early embryonic lethality by $\mathrm{p} 53$ or p21 null mutation. Nat Genet 16: 298-302, 1997.

25. Jonkers J, Meuwissen R, van der Gulden H, Peterse H, van der Valk M and Berns A: Synergistic tumor suppressor activity of BRCA2 and p53 in a conditional mouse model for breast cancer. Nat Genet 29: 418-425, 2001.

26. Greenblatt MS, Chappuis PO, Bond JP, Hamel $\mathrm{N}$ and Foulkes WD: TP53 mutations in breast cancer associated with BRCA1 or BRCA2 germ-line mutations: Distinctive spectrum and structural distribution. Cancer Res 61: 4092-4097, 2001.

27. Bernardini MQ, Baba T, Lee PS, Barnett JC, Sfakianos GP, Secord AA, Murphy SK, Iversen E, Marks JR and Berchuck A: Expression signatures of TP53 mutations in serous ovarian cancers. BMC Cancer 10: 237, 2010 